Jan Bičovský

\title{
PROTO-INDO-EUROPEAN LARYNGEALS AND VOICING ASSIMILATION
}

\begin{abstract}
In recent Indo-Europeanist literature, it is common to encounter statements concerning phonological feature [voice] and PIE laryngeals in a wide spectrum from explicit commitment to specific feature-segment combinations to reserved observations on possibilities and probabilities. This article aims to consider some implications of these statements, the possibilities to prove or disprove any such claims through distributional patterns of the relevant segments. Namely, I consider their presence in consonant clusters that should show traces of voicing assimilations if laryngeals were phonologically +/-[voiced]. I will argue that the implications involved in a strong commitment to the [voice] as a phonological feature in PIE laryngeals is not warranted by data, which may either mean that the feature was not phonologically relevant, or cannot be shown with any certainty to be the property of any of the three segments in either of its values, + [voiced] or -[voiced]. This is in principle reconcilable with laryngeals-qua-fricatives in as much as they are reconstructed as having sonorant allophones in consonant clusters, for which there is typological support from Cairene Arabic.
\end{abstract}

\section{KEYWORDS}

Proto-Indo-European; laryngeal theory; voicing

\section{Introduction}

With a few exceptions (notably DE SAUSSURE 1879; ReYNolds et al. 2000; KeSSLER (n.d.)), PIE laryngeals are considered to have been part of the obstruent subsystem of the PIE phonology, that is stops and/or fricatives. In spite of the lack of a communis opinio on both their articulatory position and possible secondary features (labialisation and such), this much seems to be the prevailing position among scholars (MEIER-BRÜGGER 2010, 237; ForTSON 2010, 64; BEEKES 2010, 119, 147). Recent literature on PIE phonology agrees on ${ }^{*} h_{2}{ }^{*} h_{3}$ having been continuants 
(mostly identified with post-velar fricatives), while for ${ }^{*} h_{1}$ the majority position likewise appears to favour a (glottal) fricative, thus bringing the three phonemes into line, while a group of scholars mainly related to the so-called Leiden school support a glottal stop (BEEKEs 2010). For the purposes of this article, this last problem is irrelevant - whatever assumptions I shall make with implications for the effects of sonority in laryngeals-qua-fricatives should also hold for less sonorous segments, such as affricates and stops.

This treatment of laryngeals as a separate class of (continuous) phonemes in PIE is supported by a number of features that the laryngeals share (among them being vocalisation, effects on prosody in Balto-Slavic, or assimilation to vocalic segments). It is a matter of debate to what degree should then assumptions about sonority of one member of this class require subsequent assumptions concerning the class as a whole and all its individual members.

One more point of contention among experts on PIE phonology is the presence of the phonological feature of voice in laryngeals and consequently their position on the sonority scale and relation to other classes of consonants. As this crucially depends on the presence of this feature in the PIE obstruent system as such, this debate is relevant only within such frameworks which consider [voice] as a feature of the PIE stop system. Here I follow the traditional system as presented in MeierBrügger (2010), but it should be clear that some of my arguments would either be irrelevant or would require different formulation under any of the "glottalic" approaches (the "modern" approaches presented as such by BEEKES 2010) - e.g. what feature should we reconstruct for ${ }^{*} h_{3}$ (different, presumably from the mainstream [voice] as reconstructed by Beekes for $\left.{ }^{*}{ }^{*}\right)$ to account for the assimilatory change in ${ }^{*} p>{ }^{*} b$, or in Beekes' terms ${ }^{*} p:>{ }^{*} p$ ?

Although the feature of voice in laryngeals is seldom discussed in detail by the current works of reference, ${ }^{1}$ it is often either explicitly stated or arguments for its presence are implicit in the attempts to employ a voiced ${ }^{*} h_{3}$ to solve a very limited number of cases where for no apparent reason PIE voiceless stops surface as voiced in some languages, most notably the reduplicated present of the verb * peh $_{3}(i)$ 'to drink', where the assumed PIE reduplicated present " piph $_{3}$ e- evolves into Ved. piba-, Lat. bib- and Old Irish ib-.

This is precisely the kind of hypothesis which inspires a questions of broader implication: 1 ) if ${ }^{*} h_{3}$ triggers voicing assimilation and is therefore phonologically

1 Compare e.g. Fortson $(2010,64)$ "As regards their phonetic character, one fairly widespread view has it that ${ }^{*} h_{1}$ was a simple $h$ or a glottal stop [?], ${ }^{*} h_{2}$ a voiceless pharyngeal fricative [ $\left.\hbar\right]$ (same sound as the Arabic letter $h$ '), and ${ }^{*} h$ a voiced pharyngeal fricative [ $\varsigma$ ] (same sound as Arabic 'ayn); but there are other possibilities as well." Kümmel $(2012,4)$ opts for a triad $[h][\chi][b]$, but never the less proposes a different mechanism to account for the pibati problem, i.e. "Final voicing = nonexplosive articulation; perhaps also syllable-finally, preserved in ${ }^{*} p i-b \$ h_{3}-V$ etc. - isolated example(s) of older more general rule?" In the same vein many others, e.g. Lehmann (1952). 
+[voiced], are the other two members of the same class phonologically -[voiced]? And if not, is this an argument against considering all three a phonological class despite other obvious commonalities? 2) Do laryngeals as a class conform in this respect to the behaviour of other obstruents in the vein of Byrd $(2015,12)$ “* $/ \mathrm{h}_{3} / \mathrm{par}$ ticipated in voicing assimilation (a process restricted to obstruents; see 5.1.), most famously in */pi-ph -e-ti/ $\rightarrow$ * pibh eti 'drinks' > Ved. píbati, OIr. -ib, Lat. bibit, Arm. ampē."? 3) Do all the other cases of reconstructable tenuis+ ${ }^{*} h_{3}$ clusters conform to this hypothesis, and if not, are the arguments that can be provided for contradictory cases as strong or stronger than those that inspired the original hypothesis in the first place (more precisely, are they less ad hoc and more grounded in phonological or typological observations)? How can this be tested and proved or disproved?

In effect, the question raised by this article is - what do we mean (if anything) by claiming that laryngeals were phonologically voiced or voiceless, especially if it were the case that unlike their colouring effect on vowels or their propensity to vocalise this feature cannot be retrieved from their effects on their immediate context and if the very material upon which the current hypotheses were formulated is meagre and problematic.

Byrd's $(2015,11)$ explicit statement, echoing his treatment of the same problem "Though continued exclusively as vowels in many of the daughter languages, it is very likely that the laryngeals were all fricatives of some sort, both phonetically and phonologically [emphasis JB]."2 raises questions as to the degree to which the behaviour of the best attested and arguably the only secure PIE fricative, *s, should guide our reconstruction in relation to laryngeals, especially in respect to voicing assimilations concerning * ${ }^{*}$ as target or trigger. That is, if all obstruents are marked for voice, all fricatives are obstruents, and all laryngeals are fricatives, does that imply that laryngeals were phonologically $+/$-[voiced]?

Though it is mainly arguments from syllable structure that lead Byrd (2015, 11, fn. 14) to assume that "[ $t$ ] he laryngeals pattern with the one assured fricative in PIE, *s, in the general root template ${ }^{*}\left\{s, h_{x}\right\} \operatorname{PRVR}\left\{s, h_{x}\right\} P\left\{s, h_{x}\right\} . "$, it should be noted that *s does not pattern with laryngeals in other respects, most notably in vocalising and apparently not in voicing assimilations of the kind proposed for *s by Siebs's law. ${ }^{3}$ Whether this is due to features specific to non-oral fricatives or the result of categorical difference between*s and laryngeals is also the topic of this article.

Our understanding of the voicing assimilation of PIE obstruents in general depends especially on the shared lexical items that can be safely projected to the

2 Byrd $(2015,12)$ provides a list of arguments for their status as fricatives rather than vowel (pace REYNOLDS et al. 2000), and lists the voicing effects of ${ }^{*} h_{3}$ as one of three main arguments: "and (at least) */ $/ h_{3} /$ participated in voicing assimilation".

3 Unlike *sT- clusters, which according to Siebs' law allow only *s+tenuis, laryngeals, which are reconstructed for this position in a great number of roots and combinations of ${ }^{*} h_{1-3}$ and T-M-MA, do not trigger any such change and the distribution of stops is not constrained in this position. 
proto-language principally in those language which preserve this feature in their repertoire. Two separate observations can be made: 1) all obstruents within a cluster share the same value of the feature [voice] 2) with the exception of Indo-Iranian (Lex Bartolomae which renders the clusters ${ }^{*} \mathrm{C}^{\mathrm{h}} \mathrm{C}$ as $\mathrm{C}^{(\mathrm{h})} \mathrm{C}^{\mathrm{h}}$ ) all other languages point to regressive assimilation of voice.

This will be the null hypothesis here, against which laryngeals will be tested. ${ }^{4}$

\section{$1.1 \mathrm{Th}$-clusters}

Unlike the embarrassing shortage of good provable material on $\mathrm{Th}_{3}$-clusters, sequences of stop $+{ }^{*} h_{2}$ are numerous in the reconstruction. Although Penney states (1988-1990) that "[i]t is quite commonly held that ${ }^{*} h_{2}$ was distinctively voiceless on the strength of the Indo-Iranian treatment of voiceless stop $+{ }^{*} h_{2}$, which yielded a voiceless aspirate", this should better have been phrased as "voiceless stops remain voiceless before ${ }^{*} h_{2}$ (just like before vowels and resonants)." There are numerous examples where in fact media $+{ }^{*} h_{2}$ result in voiced aspirates in Indic ( ${ }^{*}$ mégh ${ }_{2}$ 'big' $>$ Ved. máhi, * ${ }^{h} u g h_{2} t e \bar{r}>$ duhitā-), but since no such behaviour can be seen in any other IE branch preserving three distinct reflexes of the three PIE series, it must at least in part be an inner-Indo-Iranian development.

Likewise, the universal shift of TH to geminate/fortis stops in Hittite (cf. KLOEKHORST 2008,79 ) merely shows that in this position laryngeals had an effect on Proto-Hittite or Proto-Anatolian stops for what they were phonologically - the growing consensus points in the direction of lenis vs. fortis stops. The equation of Hitt. mekki 'much' with Ved. máhi and Gk. $\mu$ 'r $\gamma a$ shows that either there had been independent analogical restoration of a PIE *mék $h_{2}<{ }^{*} m e ́ g h h_{2}$ in Greek and Indo-Iranian, or Hittite development is an independent innovation. I assume that Melchert (1995, 76) refers to Proto-Anatolian ${ }^{*} h_{2}$, for which there is evidence in Hittite to have been voiceless: "Given the evidence that ${ }^{*} h_{2}$ is voiceless, I prefer to assume that the stop becomes voiceless by regressive assimilation and ${ }^{*} h_{2}$ is then lost as usual between stop and vowel (so Winter apud KURYLOWICZ, 1958, 251, and WATKINS 1975a, 376). The alternative assumption of progressive assimilation to a geminate voiced stop (e.g. JASANOFF 1979, 87) cannot be entirely ruled out."

I cannot see how either Greek or Indo-Iranian can be reconciled with a phonologically voiceless ${ }^{*} h_{2}$. Note also in relation to the supposed voicing effects of ${ }^{*} h_{3}$ (below) that in most environments where ${ }^{*} h_{3}$ survives as a consonant in Hittite, it

4 Byrd $(2015,22)$, citing Mayrhofer $(1986,110)$ writes that "If an underlying voiced or voiced aspirate obstruent precedes another obstruent, it assimilates its laryngeal features to the following consonant.", but among the environments that may not provoke this behaviour are "perhaps laryngeals." It is therefore difficult to see where Byrd stands on the obstruent character of laryngeals or whether this is in fact an unperceived contradiction to his other claims concerning this subject. 
has merged with the reflexes of ${ }^{*} h_{2}$ and most likely its effects on preceding stops were similar.

\section{Indirect evidence}

Unlike other obstruents, laryngeals do not (with few notable exceptions) surface as obstruents in the daughter languages and we must depend on consideration of their effects on their phonetic environment as much as it can be gleaned from the data. This is as much the case with voicing effects as with vowel colouring. In this respect, it is relatively more difficult to present material in which one can identify an individual laryngeal as a segment in a given context with sufficient certainty. For this reason, it is suitable to restrict ourselves to cases of inlaut clusters as a) morphemes (for reasons of PIE morphology mostly roots) are rarely represented in lexical material of multiple IE branches with anlaut variants depending on context (possible candidates are among compounds, the verbal reduplicated intensive, and some early preverbs - which may have problems of their own in their phonology) b) the behaviour of auslaut clusters in which laryngeals are the second member may also be influenced by effects of the pre-pause position. Thus the ideal testing terrain is a sequence -VTHV- (where T stands for any stop, since the only other fricative in the system, ${ }^{*}$ s, while provoking voice assimilation does not have a voiced counterpart).

Synchronically (on the late PIE level) medial $\mathrm{TH}^{5}$ clusters are of three kinds 1 ) the result of ablaut alternation of a TVH morpheme - zero grade - TH- before a vocalic segment 2) analysable into two separate morphemes - that is segments on both sides of a morpheme boundary - be it root+suffix, suffix+ending, suffix+suffix or root+ending 3) synchronically unanalysable into separate morphemes. Each of these types has its problems and its strengths. Both 1) and 2) are relatively more vulnerable to the effects of analogical changes but other instances of the same morphemes in different environments may increase the probability that a laryngeal (ideally even the individual laryngeal ${ }^{*} h_{1}$ to ${ }^{*} h_{3}$ ) has been safely reconstructed. In 3), the effects of possible analogical change cannot be discounted but are relatively lower, as the potential source of analogy must lie beyond an inflectional or derivational paradigm, but the same etymological isolation means that some of the tools of comparative reconstruction cannot be implied with sufficient reliability. I will first consider these three types in general terms.

5 As far as I know, little attention has been paid to the -TH- clusters as regards voicing assimilation triggers by laryngeals. Penney (1988-1990, 366-367) examines the clusters -HT- (primarily ${ }^{*} h_{2} T$ ) concluding that "there was no obvious preference, let alone restriction concerning, combinations of ${ }^{*} h_{3}$ with a voiced stop, ${ }^{*} h_{2}$ with a voiceless one." This is mainly in the context of positing [voice] as the main distinguishing feature of ${ }^{*} h_{3}$ and ${ }^{*} h_{2}$. 


\subsection{The result of ablaut alternations}

For reasons of the reconstructable inventory of PIE morphemes, and the particular organisation of its morphology and morphophonology, a medial cluster of $\mathrm{TH}$, in which both segments pertain to the same morpheme can be obtained by an ablaut reduction of a morpheme of the structure $-\mathrm{TeH}$. There are only a limited number of suffixes that fulfil this requirement, among them the compound abstract suffix ${ }^{*}-t-e h_{2}-$, which could in principle reduced to ${ }^{*} t-h_{2}$ - and thus could provide an argument for ${ }^{*} h_{2}$ being voiced (provided it was unanalysable into two distinct morphemes in late PIE, which cannot be guaranteed).

The number of roots (mostly verbal) which fit this description is considerably larger. For these roots to provide the required sequence, one would need to identify PIE lexemes where the root is not the initial morpheme in the word and at the same time, the suffix has a vocalic onset. Among nouns, such derivations may have been numerous, especially prefixed deverbal o-stems. In practice, few are securely reconstructable for PIE. In this way, Ved. nibha- 'similar', if indeed from ${ }^{*} n i-b^{h} h_{2}-o-$, and IF of PIE age, provides a cluster where, based on comparative evidence, the root is * $b^{h} e h_{2}$ 'to say' - and where no assimilatory change can be discerned. Whether this is a genuine continuant of a PIE ${ }^{*}-b^{h} h_{2}$ - is dubitable and certainly difficult to prove with enough certainty to count as a piece of decisive data. Other such examples are of the same nature.

A supposed piece of evidence in favour of a voiced ${ }^{*} h_{3}$ is provided by Rix $(1976$, 172), by the unexpected Gk. ordinal number oै $\gamma \delta \circ o$ ' 'eight', which starts from a PIE ${ }^{*} h_{3}$ éktoh ${ }_{3}$ 'eight' which should yield ${ }^{*} h_{3}$ ékth $h_{3} u$ - first yielding *ogduuos with subsequent vowel lowering and regular - w- elision. This implies that the Proto-Greek form, probably an independent innovation rather than an inherited ordinal, had both vocalised the laryngeal and (prior) to this vocalisation undergone a voicing assimilation. This relies on a number of ad hoc assumptions none of which can hold under closer scrutiny. Beekes $(2009,1044)$ is not convinced, arguing that Rix (1976) ${ }^{*} h_{3} e k t h_{3} u h_{2} 0-$, the original source of this hypothesis, is ad hoc. An analogy with

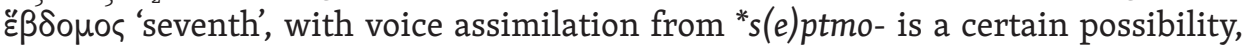
although the nature of analogy is anomalous but perhaps can be accepted within the otherwise analogy-ridden realm of numerals (note that RIX 1976, 172 employs the same strategy to explain है $\beta \delta o \mu o s$ itself). In the same way, Penney (1988-1990, 366) comments on ${ }^{*} h$, citing Mayrhofer $(1986,143)$ for the objections to this hypothesis on the grounds of píbati being the sole good example. Note that while there is independent support for some change occurring in PIE *septmo- in Slavic *sedms (although this may in fact be little more than a typological parallel), o' $\gamma \delta 0$ s is a uniquely Greek innovation and of the three examples on the voicing effects of ${ }^{*} h_{3}$ by far the least persuasive.

Among verbs, it was the thematic derivations from zero grade which provided the first and so far best evidence for the voicing in ${ }^{*} h_{3}$. According to LIV, there are 
no reduplicated thematic derivations from any ultimae laryngalis roots, apart from ${ }^{*}$ peh $_{3}(i)$ 'drink', no reduplicated aorists with a stop onset in the root, and no case of thematic derivation from zero root. In essence, there is no evidence to either corroborate or disprove the proposed voiced character of ${ }^{*} h$.

The facts of the * peh $_{3}(i)$ 'drink' (LIV 462-463) are well known. While all the nominal derivations and most verbal derivations of this root point unequivocally to a PIE * $p$, a well-attested group of reduplicated thematic verbs including Ved. píbati, Latin bibit, Old Irish ibid, and Arm. ompem point to a PIE [píb]. This unexpected behaviour led to the hypothesis that ${ }^{*} h_{3}$ was voiced. This scenario has gained prominence among scholars. Other possible explanations cannot be disproved but given that they would necessarily rely on mechanism that are considered less regular and more speculative than sound change (although a case of unus testis nullus testis). Given that the original meaning of the root seems to have been 'gulp' rather than 'drink' (LIV 462, on Hittite evidence), one could easily envisage that the change to a highly marked ${ }^{*} b$ at some point was part of an onomatopoeia or was due to child language. Standing apart, this may be a weaker explanation, but considering the implications of the ad hoc sound law, may in fact be preferable.

\subsubsection{Schwebeablaut and root enlargements}

Further light on this problem could be shed if in any of the Schwebeablaut roots as ${ }^{*} h_{2}$ eug $\sim{ }^{*} h_{2}$ weks 'grow', laryngeals stood in the coda position. Unfortunately, none such are known (e.g. none listed in $\mathrm{LIV}^{2}$, the important pioneering work by Anttila (1969) provides little support for the complex structures of roots as reconstructed nowadays). The only possible root in LIV is ${ }^{*} d^{h} e{ }^{w h} h$, which may have had a secondary ablaut variant ${ }^{*} d^{h} g^{w h} h_{2}$ - or, if in fact we deal here with a root-enlargement in ${ }^{*}-h_{2}$, this would presuppose a chain of derivation and apophony ${ }^{* *} d^{h} e g^{w h}+{ }^{* *} h_{2}=>$ ${ }^{* *} d^{h} g^{w h} e h_{2}={ }^{*} d^{h} e g^{w h} h_{2}$. Even if in fact this is a plausible explanation, it does not provide much evidence.

\subsection{Morpheme boundaries}

This class of examples can be further subdivided according to the type of morphemes in the sequence. Both ${ }^{*} h_{1}$ and ${ }^{*} h_{2}$ are regularly reconstructed as initial segments in a number of suffixes and endings, roots with ${ }^{*} \mathrm{He}$ - onset are likewise numerous, but again, less likely to provide us with any probative lexical material.

\subsubsection{Root+suffix}

A possible advantage of this sequence (compared to the root+ending or suffix+ending type) is the possibility of a semantic change of the given lexeme which may render the sequence of two morphemes unanalysable and less susceptible to analogy. Suffixes with (supposed) laryngeal onset are reasonably well attested. 


\subsubsection{1 $* \boldsymbol{h}_{\mathbf{1}}$}

The existence of a separate nominal ${ }^{*} h_{1}$ - derivation is dubious (of the type of Lat. fidès etc.) and not attested in a sufficient number of items and languages to be able to support possible allomorphy by material. As to the problem of the so-called Hoffmann suffix, this I will treat in detail below under ${ }^{*} h_{3}-$. The one verbal suffix, for which a ${ }^{*} h_{1}$-onset is reconstructed, the so-called essive in ${ }^{*}-h_{1} j e ́-$, is problematic in that it is not obvious under what conditions, if any, the laryngeal could have been prevocalic. The Sievers's law mandates that after a sequence of two (and more) consonants, a semivowel (or maybe any resonant) becomes syllabic, thus a possible allomorph of *-hjé- is * ${ }^{*} h_{1} i j e ́-$, and given PIE roots always consist of at least two consonants, more often than not the conditions for Sievers's law would have been fulfilled. In *- ${ }_{1} i j e$ - thus the laryngeal should have disappeared without trace. However, the very reconstruction rests on the fact that we find evidence for a vocalic reflex of ${ }^{*} h_{1}-$, which in turn requires a consonantal ${ }^{*} j$, and disqualifies this suffix as a possible (de)voicing trigger. In any case, none of the reconstructed essive derivations exhibit any traces of voice alternation in the root.

\subsubsection{2 ${ }^{*} \boldsymbol{h}_{\mathbf{2}}-$}

In terms of lexicon, this laryngeal is among the three most frequent consonantal segments in PIE and is present in the onset a number of productive suffixes (e.g. collective, the various other nominal ${ }^{*} h_{2}$-stems), the derivations of which survive in numerous languages. As for collectives to roots (or suffixes) in - T, the shift of this derivation towards a case form makes it difficult to disprove effects of paradigmatic analogy (and there are no traces of any voicing assimilation in IE languages in this derivation). Among the other ${ }^{*} h_{2}$-derivatives (some of them possibly also collectives at some stage), such as abstracts and feminines, the respective derivations either include within the inflectional paradigm the allomorph ${ }^{*}-e / \mathrm{oh}_{2}^{-}$, where the stop and the laryngeal are separated by a vocalic nucleus, or are in fact already levelled in favour of this allomorph. An ideal candidate would be an acrostatic ${ }^{*} h_{2}$ stem with a T-coda, but evidence is lacking.

\subsubsection{3 ${ }^{*} \boldsymbol{h}_{3}-$}

The very existence of any suffixes with ${ }^{*} h_{3}$-onset depends on the evaluation of data in a derivation identified by Hoffmann (1976) and known as the Hoffmann suffix. On the level of daughter languages, this suffix surfaces as a sequence of a vowel $+n$, without any consonantal trace of the laryngeal. The sole piece of evidence for the identification of the laryngeal in this suffix as ${ }^{*} h_{3}$ and at the same time one of the few pieces of evidence for it being phonologically voiced, is the Celtic etymon *abōn, as reflected in Old Irish $a b$ 'water' and possibly in Het. hapa- 'river', where - $p$ - cannot represent a reflex of PIE tenuis (although in this case, a simple o-stem derivation 
cannot be excluded (WoDTKo et al. 2008, 315) and the lexical equation and involvement of the Hoffmann suffix is dubious). Both the scarcity of evidence for PIE *b, and the obvious similarity to the widely attested family of PIE * $h_{2} e p$ - 'water' could point to an original PIE ${ }^{*} h_{2} e p$-Hon- 'having waters', which may have shifted from an original epithet 'having (a lot of) water' to simply 'a body of water' by a series of trivial semantic shifts. The voiced labial has been accounted for by as due to the initial laryngeal in the Hoffmann suffix being ${ }^{*} h_{3}$, which had been reconstructed as voiced on the basis of the famous píbati family and used in a rather circular manner as further proof of the hypothesis. Of course, the possibility of two different roots for PIE cannot be excluded, and e.g. Kloekhorst (2008, 294-295) supports this position. Note also, that it is hardly an exception in PIE lexicon for a root to have variants in final tenuis and media, e.g. 'peh $\hat{k}_{2}$ 'fest warden' and *peh $\hat{k}$ 'festmachen' LIV (461), *peik 'heraushaunen, herausschenieden' LIV (465) and 1. *peig 'malen' LIV (464) to name but two. It would appear that the apparent allomorphy in ${ }^{*} h_{2} e p{ }^{*} h_{2} e b$ is not isolated and as long as it fits within a larger group of examples (admittedly still without a good explanation) it should be first as part of this group that it should receive attention. The whole idea has been dismissed by a number of scholars (see MEIER-BRÜGGER 2010, 249).

Again, to prove or disprove this unus testis hypothesis, one should examine all possible derivatives which fulfil the conditions of $-\mathrm{T}+{ }^{*} h_{3}$ on-. However, if the Palaic hapax malitanna- 'bee' can be securely connected with this suffix, as per Olsen (2004, 229-238) as 'having honey', the -t-may reflect another example of the same phenomenon, or it may not, as Melchert $(1994,6)$ accounts for this - $t$ - /d/ as “" probably" a lenition of PIE voiceless stops and ${ }^{*} h_{2}$ after a P[roto]A[anatolian] unaccented vowels...", which does not exclude the possible voicing, but for the same reason neither can it guarantee it. In the same vein, Kloekhorst $(2008,580)$. Other examples, to my knowledge, are missing. On the whole, proof for voicing in ${ }^{*} h_{3}$ can hardly rely for support on the Hoffmann suffix.

\subsubsection{Root/suffix+ending}

Numerous endings in PIE consisted of a laryngeal or had a laryngeal onset. To my knowledge, there is not one piece of evidence from IE languages that any kind of assimilation on this morpheme boundary survived as a synchronically unmotivated allomorphy - which is hardly a remarkable fact as analogical change would have erased such traces rather quickly unless some unpredictable lexicalisation intervened. To be more specific, we have no traces of any assimilations of the stem-final segment in the nom.acc. pl. neut. of consonantal stems to yield e.g. Ved. *adánthi instead of adánti from * $h_{1}$ dont- $h_{2}$ 'the eating (things)', the original presence 1.sg. perf. ${ }^{*}-h_{2}$ does not lead to Ved. *tutódha 'I (have) struck' from PIE * $(s)$ teu-toud- $h_{2}$ e etc. No nominal or verbal endings, as far as can be ascertained, contained ${ }^{*} h_{3}$. 


\subsection{Synchronically morphologically unanalysable clusters}

Another type of evidence comes from the sequences of $\mathrm{TH}$ within a single morpheme. Here the possibility of analogy is relatively lower. Such groups can indeed be identified in a number of verbal roots (following LIV², with addenda by KüMMEL 2015) and in a number of endings. The verbal roots ending reconstructed with various degrees of certainty as ending in $-\mathrm{TH}^{6}$ are in fact rather numerous and the distribution of the three laryngeals in relation to the three types of PIE stops can be briefly summarised:

Tab. 1 Distribution of IE sequences plosive+laryngeal

\begin{tabular}{|l|c|c|c|}
\hline & ${ }^{*} h_{1}$ & ${ }^{*} h_{2}$ & ${ }^{*} h_{3}$ \\
\hline$T$ & 0 & 18 & 1 \\
\hline$M$ & 0 & 4 & 0 \\
\hline$M A$ & 1 & 1 & 0 \\
\hline
\end{tabular}

It is difficult to judge whether this distribution is surprising. On the face of it, ${ }^{*} h_{2}$ is disproportionally more frequent in this position than either ${ }^{*} h_{1}$ or ${ }^{*} h_{3}{ }^{7}$ This is evident if other types of roots (e.g. with final - $\mathrm{RH}$ ) are taken into account. While ${ }^{*} h_{2}$ still appears to be the most frequent laryngeal in this position, the distribution is more even and can be said to reflect the overall frequency of all the laryngeals in PIE lexicon in general. One cannot, however, hasten to generalise this distribution into a law of distribution, and to hypothesise that only ${ }^{*} h_{2}$ was ever present in the *-TH coda in PIE roots, in the vein of Benveniste's constraints on root structure with obligatory onset and coda, which often requires the reconstruction of ghost laryngeals which cannot be supported by data. It is certainly possible that even the few examples of ${ }^{*} h_{1}$ and ${ }^{*} h_{3}$ are more a product of overreconstructing for the sake of not omitting possible PIE segments rather than firmly established facts. The 25 odd roots with ${ }^{*}-T h_{2}$ are hardly a sufficient material to allow for any other observation

6 It is possible, and in fact advisable, to consider the roots not in the ideal abstract form, but also the environments in which the sequence - $\mathrm{TH}$ - was most likely to appear. Given the preference for consonant-initial affixes in PIE, more often than not this sequence would have been potentially vocalised, or the laryngeal may have been deleted by one of a number of such processes in PIE (BYRD 2015, 26-27) and we cannot exclude (or prove) the possibility, that these clusters were regularly broken up by a prop vowel which - if voiced itself - would preclude direct contact between the stop and the laryngeals and for this reason this group of examples is worthless as evidence. Then again, why this should have not been the case in other situations remains a problem.

$7 \quad$ This has been reflected by one of the authors of LIV, M. Kümmel $(2012,13)$ : "Root type *oTH-: ${ }^{*} \chi\left[={ }^{*} h_{2} \mathrm{JB}\right]$ clearly overrepresented in LIV, but reconstruction of * $\chi$ more often than not circularly reconstructed from IIr. aspiration only $\Rightarrow$ some may have had * $h$." The problem here is, whether it can be independently established that * $h_{1}$ had aspirating effects on other data and then, if in fact this is not tantamount to say that all the $-\mathrm{TH}$ roots with the laryngeal established solely on the basis of Indo-Iranian data should not in fact be then reconstructed with the unspecified * ${ }^{*}$. 
than the mere fact that overall PIE tenues are more frequent as such and would be expected then to be more frequent in this environment as well.

Returning to the question of the possible traces of voice in the environment of ${ }^{*} h_{3}$, it appears that PIE ${ }^{*} h_{2} e k h_{3}$ speaks against a voiced ${ }^{*} h_{3}$, but the basis on which

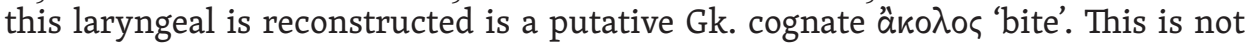
an isolated case. The very presence and identity of the laryngeal in this position is frequently questioned, another such case being the root ${ }^{*} w e d^{h} h_{1}$. In fact, of the three examples of ${ }^{*} h_{1}$ and ${ }^{*} h_{3}$, none is quite secure. On the other hand, establishing the identity of any laryngeal in this context is problematic. In LIV, there are further 11 roots with uncertain laryngeals. Clearly, if any voicing and devoicing effects of laryngeals could be established, some of these cases could be clarified. The addenda to LIV (KÜMMEL 2015) have added some new roots to the list and deleted others.

The significance of these groups for the reconstruction of voice in laryngeals is clear. As speakers were unlikely ever to encounter any other form of the root these groups were not liable to ablaut - there was no way in which they could intuit a different phonological status of the stop from the surface form - which in turn should have depended on its laryngeal features to the following laryngeal - provided laryngeals triggered voice assimilation.

\subsection{PIE endings}

Among PIE endings, a limited number of -TH- sequences can be reconstructed namely:

$2^{\text {nd }}$ sg. *-the is based directly on Ved. -tha, and is supported by data from other languages.

$2^{\text {nd }}$ pl. mediopassive ${ }^{*}-d^{h} h_{2}$ we (the presence of the laryngeal is now supported by Kim (2019) on the basis of the fortis - tt- in Hittite -ttuma-,

which point to opposite direction as far as the effect of the laryngeal are concerned.

(Possibly also $2^{\text {nd }}$ pl. pres. act. on the strength of Ved. -tha, where the presence of an original ${ }^{*} h_{2}$ is contradicted by the forms in other languages, such as Gk. $-\tau \varepsilon$ and if this form is a direct continuation of a PIE ending and not an internal Indo(-Iranian) innovation, it would point to a sequence ${ }^{*}$-the with an isolated case of aspiration by ${ }^{*}-h_{1}$.)

\section{Two options for fricatives}

On the basis of our data, it seems that laryngeals did not trigger voicing assimilation, as examples can be provided for almost any combination of PIE stop and PIE 
laryngeals. It has been suggested in previous research (e.g. PENney 1988-1990) that it cannot be shown that laryngeals themselves were targets of voicing processes either. Yet it remains a distinct possibility, in fact one of two possibilities if they are to be regarded as fricatives. Either they were a special class of fricatives which did not trigger voicing assimilation, or in fact they were subject to progressive assimilation. On the surface level, this would yield exactly the same outcome, provided no two laryngeals were distinguished solely on the basis of this feature and would not thus neutralize in these contexts. This I believe can be safely rejected on the grounds of their different colouring effects which cannot be explained merely by the presence of [voice], unless this feature in turn does not provoke sufficient shifts in articulatory position.

\subsection{Progressive assimilation}

Progressive assimilation of at least ${ }^{*} h_{2}$ is required to account for the behaviour of this laryngeal in clusters with tenues and with mediæ in Indo-Iranian. In both cases, the result is an aspirated stop with the corresponding value of [voice] dependent on the stop. If this had been the case in in other languages is apparently impossible to prove or disprove, as laryngeals do not surface as aspiration. Greek does present some examples which may be presented in these terms, e.g. 2.sg. perf. - - $\checkmark a$ with aspiration possibly from PIE ${ }^{*}-t_{2} e$, but as voiced aspirates become unvoiced in Greek, it cannot be shown whether regressive assimilation took place or not.

From the typological perspective, examples of regressive assimilation in fricatives are not lacking and if the condition for perfect match between all obstruents in PIE is dropped, laryngeals can easily be seen as phonologically marked for voice, yet never triggering assimilatory changes. One obvious example of a fricative which though voiceless does not trigger voicing assimilation is English glottal fricative (probably $={ }^{*} h_{1}$ ), as can be shown by such examples as (across morpheme boundary) withhold [wiðhould] or [wiðhhould] or regularly in sequences of like of him [əvhim] or [əvhhim] though one may object that the since the contrast in English is not one of voice but rather of lenis-fortis this cannot be readily superimposed on the PIE situation under the standard scenario.

Ancient Greek may in fact present examples of the same phenomenon. As stops can only appear in auslaut due to elision before a vocalic onset, one can adduce the different behaviour of final $-\tau$ and $-\delta$ before spiritus asper, where in the case of a voiceless segment, the resulting sequence is $-\vartheta \# \mathrm{~V}-$, while $-\delta$ shows no effects of devoicing or aspiration and it is the glottal fricative which undergo a deletion.

\subsection{No assimilation}

Another possibility is for laryngeals to have been phonologically voiced or voiceless and yet inert to assimilation both as targets and as triggers. Such patterning could either result from their phonetic properties or could be the outcome of a systemic 
shift in Pre-PIE of the kind suggested by e.g. Kümmel $(2012,5)$, that is ${ }^{*} h_{2}$ and ${ }^{*} h_{3}$ as deriving from uvular stops, voiceless and voiced.

\subsubsection{Phonetic properties}

As Semitic in general and Arabic in particular have served as models for the behaviour of laryngeals ever since the outset of the laryngeal theory, and this comparison proved fruitful on many levels, it may be of advantage to consider the behaviour of these segments in Arabic. According to Kabrah (2011, 29-32), behaviour of Arabic post-velars in the relevant kind of clusters is peculiar and perhaps informative for our purposes. As the morphophonology of Arabic allows for the same two radical segments to appear either in a direct sequence or separated by a vowel, roots with a stop either as the first or second radical and a post-velar fricative as either the second or third radical respectively yield enough data to conclude that while some fricatives (typically voiceless, like $\hbar$, trigger devoicing; Petr Zemánek, p.c.) others (the voiced pharyngeal fricative $\zeta$ does not). Arabic dialects may differ in this respect, but especially the data from Cairene Arabic are noteworthy, cf. Kabrah (2011, 30): "the pharyngeal $/ \varsigma /$ and the laryngeals $/ \mathrm{h} /$ and $/ \mathrm{R} /$ behave as sonorants; they do not participate in assimilation by either devoicing or spreading voice [italics JB]. Second, the uvulars $|\chi|$ and $/ \gamma /$ behave as obstruents, i.e. they devoice and spread voice in the appropriate environments. Third, the pharyngeal $/ \hbar /$ does not undergo voicing in coda position but it triggers devoicing in a preceding voiced obstruent." Fricative laryngeals with systematic sonorant allophones are an attractive solution that is harmonious with other laryngeal behaviours, first and foremost their vocalisation.

\subsubsection{Pre-PIE development}

It could also by the case that a synchronically unexpected distribution and lack of certain contextual mechanisms may result from an earlier systematic shift. Thus laryngeals qua fricatives (or obstruents) would in fact be allophones of a class of segments which is closer (and perhaps historically derived) from some class of approximants or resonants. One can think about the development of Slavic * $w$, which evolved into a labiodental fricative, yet in Czech or Russian patterns as an approximant in such sequences as $k-v$, while the rules of Czech or Russian phonology would predict a voicing assimilation before a voiced fricative (thus $\mathrm{Cz}$. $k$ vám 'to you pl.' is realised as [kva:m] while the $k$ in $k$ zámku 'towards a castle' is regularly voiced [gza:mku]. In Polish, further development in fact resulted in a regressive assimilation, so that original $-k w$ - results in $-k f-$.

In a similar manner, the result of the palatalised ${ }^{*}{ }^{j}$ in Czech and Polish which is voiced in prevocalic position, is devoiced following a voiceless stop. This typological parallel of course offers no direct solution on the PIE situation. This is in fact a position close to the original de Saussure's theory. In this way, the preferable description 
of PIE phonology with respect to laryngeals would be "a class of approximants/ resonants with fricative allophones". This in no way makes our position easier in respect to reconstructing the individual Pre-PIE approximants which should result in PIE laryngeals. As speculations on the Pre-PIE situation are notoriously difficult to support by evidence, this remains a plausible but eventually unprovable alternative.

\subsection{Other alternatives}

Methodically, it is possible to reconcile the behaviour of laryngeals in the TH context and achieve a coherent class of segments with predictable assimilatory behaviour by multiplying the number of laryngeals to four or even six, but based on the limited amount of data and the relatively low importance of this problem to the solution of other questions it is certainly not an advisable course.

\section{Conclusion}

It appears that closer examination of the distribution of laryngeals in the contexts where they should reveal their phonological properties of + [voice] or -[voice] shows that neither is there any recognizable pattern to allow for a more precise description nor is the material sufficient enough to discard any of the possibilities offered above in §3. Thus, referring to laryngeals as "voiced" or "voiceless" in the same manner as voiced stops or voiced vowels is not based on a comparably solid evidence and may in fact be misleading in particular cases, as in the case of ${ }^{*} h_{3}$ where it provoked a cadence of obscurum per obscurius ad hoc etymologies and implied statements on the features of the PIE phonological system.

A possible typological parallel in Cairene Arabic may at least allow one to describe laryngeals as "fricatives with sonorant allophones in consonant clusters" and give perhaps some hints, together with their interaction with vowels, as to what segments they might have been. Any reconstruction presupposing a velar or uvular character for PIE laryngeals, such as Weiss $(2016,336)$ "We can have our cake and eat it too if we suppose that Nuclear Proto-Indo-European underwent a uvularto-pharyngeal shift" (referring for the original idea to KüMMEL 2007, 336) has to take into account the implications of their phonetic character.

It is also possible to account for the behaviour of laryngeals in terms of progressive assimilation, but compared to the previous scenario, this seems a less preferable solution, as there are numerous other features of these segments which would favour a sonorant interpretation (e.g. vocalisation). 


\section{REFERENCES}

Antilla, Raimo. 1969. Proto-Indo-European Schwebeablaut. Berkeley and Los Angeles: University of California Press.

BEEKEs, Robert S. P. 2009. Etymological Dictionary of Greek. Leiden - Boston: Brill.

BEEKES, Robert S. P. 2011². Comparative Indo-European Linguistics. An Introduction. Amsterdam: John Benjamins.

Byrd, Andrew. 2015. The Indo-European Syllable. Leiden: Brill.

BYRD, Andrew. 2018. The Phonology of Proto-Indo-European. In: KLEIN, Jared S. - JosePH, Brian - FrITZ, Michael, eds. Comparative Indo-European Linguistics. An International Handbook of Language Comparison and the Reconstruction of Indo-European. Berlin: Mouton de Gruyter.

ForTson, Benjamin W. IV. 2010². Indo-European Language and Culture: an Introduction. Chichester, UK: Wiley-Blackwell.

Hoffmann, Karl. 1955. Ein grundsprachliches Possessivsuffix. Münchener Studien zur Sprachwissenschaft 6, 35-40.

KABRAH, Rawiah, S. 2009. Regresssive voicing assimilation in Cairene Arabic. In: Broselow, Ellen - OuAlI, Hamid, eds. Perspectives on Arabic Linguistics XXII-XXIII. CILT 317. (Amsterdam - Philadephia: John Benjamins), 21-33.

Kessler, Bert. (n.d.). On the phonological nature of the Proto-Indo-European laryngeals. [retrieved 8-18-2019] Available at: http://spell. psychology.wustl.edu/PIE-laryngeals/

KIM, Ronald I. 2019. The $2^{\text {nd }} \mathrm{pl}$. middle ending in Proto-Indo-European. In: BolatTi Guzzo, Natalia - TARACHA, Piotr, eds. "And I Knew Twelve Languages": A Tribute to Massimo Poetto on the Occasion of His 70th Birthday. Warsaw: Agade, 295-314.

KÜMMEL, Martin J. 2007. Konsonantenwandel: Bausteine zu einer Typologie des Lautwandels und ihre Konsequenzen für die vergleichende Rekonstruktion. Wiesbaden: Reichert.

KÜMMEL, Martin J. 2012. On historical phonology, typology, and reconstruction. [retrieved on 2608 2019]. Available at: http://enlil.ff.cuni.cz/system/files/On\%2ohistorical\%2ophonology.pdf

KÜMMEL, Martin J. 2015. Addenda und corrigenda zu LIV2, [retrieved on 2608 2019]. Available at: http://www.martinkuemmel.de/liv2add.html.

Lemmann, Winfred P. 1952. Proto-Indo-European Phonology. Austin, TX: University of Texas Press.

LIV $^{2}=$ RIX, Helmut, ed. 2002 $^{2}$. Lexikon der indogermanischen Verben. Die Wurzeln und ihre Primarstammbildungen. Wiesbaden: Reichert.

MelChert, Craig H. 1994. Anatolian historical phonology. Leiden: Rodopi.

MeIER-BRÜGGER, Michael, ed. 2010. Indogermanische Sprachwissenschaft. 9., durchgesehene und erganzte Auflage. Berlin: Walter de Gruyter.

MAYrhofer, Manfred 1986. Indogermanische Grammatik, Band I. 1. Halbband: Einleitung, 2. Halbband: Lautlehre (Segmentale Phonologie des Indogermanischen). Heidelberg: Carl Winter.

Olsen, Birgit A. 2004. The complex of nasal stems in Indo-European. In: CLAKson, James - Olsen, Birgit A., eds. Indo-European word formation. Proceedings of the conference held at the University of Copenhagen, 20-22 October 2000. Copenhagen: Museum Tusculanum Press, $215-248$. 
Penney, John H. W. 1988-1990. Laryngeals and the Indo-European root. In: BAMmeSBERGER, Alfred - Ziegler, Sabine, eds. Die Laryngaltheorie und die Rekonstruktion des indogermanischen Laut- und Formensystems. Heidelberg: Carl Winter Universitatsverlag, 361-372.

Reynolds, Elinor - West, Paula - Coleman, John S. 2000. Proto-Indo-European "laryngeals" were vocalic. Diachronica XVII, 351-387.

DE SAUSSURE, Ferdinand. 1879. Memoire sur le système primitif des voyelles dans les langues indoeuropéennes. Leipzig: B. G. Teubner.

WeIss, Michael. 2016. The Proto-Indo-European Laryngeals and the Name of Cilicia in the Iron Age. In: Byrd, Andrew M. - DeLisi, Jessica - Wenthe, Mark, eds. Tavet Tat Satyam: Studies in Honor of Jared S. Klein on the Occasion of his Seventieth Birthday. Ann Arbor: Beech Stave Press, 331-340.

Wodtko, Dagmar S. - Irslinger, Britta - SchneIder, Caroline. 2008. Nomina im Indogermanischen Lexikon. Heidelberg: Winter.

\author{
Jan Bičovský \\ Institute of Comparative Linguistics \\ Faculty of Arts, Charles University \\ nám. Jana Palacha 2, 11638 Praha 1 \\ Czech Republic \\ Jan.Bicovsky@ff.cuni.cz
}

